\title{
Association between promoter polymorphisms of OPN gene and cancer risk: a meta-analysis
}

This article was published in the following Dove Press journal:

OncoTargets and Therapy

30 December 2015

Number of times this article has been viewed

\author{
Jingwei Liu ${ }^{1-2}$ \\ Caiyun $\mathrm{He}^{\mathrm{I}-2}$ \\ Quan Yuan ${ }^{1-2}$ \\ Zhenning Wang ${ }^{1-2}$ \\ Chengzhong Xing ${ }^{1-2}$ \\ Yuan Yuan ${ }^{1-2}$ \\ 'Tumor Etiology and Screening \\ Department of Cancer Institute and \\ General Surgery, The First Affiliated \\ Hospital of China Medical University, \\ ${ }^{2}$ Key Laboratory of Cancer Etiology \\ and Prevention, China Medical \\ University, Liaoning Provincial \\ Education Department, Shenyang, \\ People's Republic of China
}

\begin{abstract}
Background: Results of the association between polymorphisms of osteopontin (OPN) gene promoter region and risk of cancer were inconclusive. The aim of this meta-analysis was to elucidate whether $O P N$ promoter polymorphisms were associated with cancer risk.

Methods: Electronic databases including PubMed, Web of Science, and Chinese National Knowledge Infrastructure were systematically searched. Odd ratios (ORs) and their $95 \%$ confidential interval (CI) were used to assess the strength of association between $O P N$ promoter polymorphisms and cancer risks.

Results: Nine studies were finally included in this meta-analysis. For $O P N$ rs 17524488 polymorphism, carriers of GG or -/G genotype were significantly associated with increased cancer risk compared with wild-type -/- carriers, respectively (GG vs -/-: OR $=1.40,95 \%$ $\mathrm{CI}=1.03-1.91, P=0.033$; $-/ \mathrm{G}$ vs $-/-: \mathrm{OR}=1.22,95 \% \mathrm{CI}=1.07-1.40, P=0.002)$. Additionally, $\mathrm{G}$ allele was significantly associated with increased cancer risk compared with (-) allele ( $\mathrm{OR}=1.21,95 \% \mathrm{CI}=1.04-1.40, P=0.016)$. However, no significant association was observed of $O P N$ rs 11730582 polymorphism and cancer risk $(\mathrm{CC}$ vs TT: $\mathrm{OR}=0.98,95 \% \mathrm{CI}=0.49-1.97$, $P=0.964$; CT vs TT: $\mathrm{OR}=0.88,95 \% \mathrm{CI}=0.54-1.43, P=0.610)$.

Conclusion: Carriers of GG or -/G genotype of $O P N$ promoter rs 17524488 (-156-/G) polymorphism might be associated with increased risk of cancer compared with wild-type -/- carriers, respectively. However, no significant association was observed between $O P N$ promoter rs11730582 (-443C/T) polymorphism and risk of cancer.
\end{abstract}

Keywords: $O P N$, promoter, polymorphism, cancer

\section{Introduction}

Approximately 12.7 million cancer cases were newly diagnosed and 7.6 million people died of cancer each year worldwide. ${ }^{1}$ As a complex multi-step disease, cancer is strongly affected by various genetic and environmental factors, of which gene polymorphism is an essential cause for the different genetic susceptibility to cancer. ${ }^{2}$ Identification of the potential genetic markers is important for screening, early diagnosing and predicting the occurrence of cancer.

Osteopontin (OPN), alternatively known as secreted phosphoprotein 1 (SPP1), is involved in a series of physiological and pathophysiological processes including cell attachment, proliferation, migration, invasion, tissue remodeling, bone formation, and inflammation. ${ }^{3}$ As a member of the SIBLING (small integrin-binding ligand $\mathrm{N}$-linked glycoproteins) family that includes five members of secreted proteins, OPN can modulate cell behavior by both autocrine and paracrine mechanisms interacting with cell surface receptors such as integrins. ${ }^{4} \mathrm{OPN}$ has been reported to be expressed within tumor cells as well as in the surrounding stroma of multiple human cancers, providing a relation with malignant invasion. ${ }^{5}$ Additionally, it has been shown that $\mathrm{OPN}$ is frequently overexpressed in numerous cancers and contributes to the formation 
and progression of tumor. ${ }^{6}$ Considering the potential role of OPN in the initiation and development of cancer, much attention has been paid to the relation of OPN with various types of cancers.

Human $O P N$ gene is located on chromosome 4q21-q25 and spans approximately $11 \mathrm{~kb}$, consisting of seven exons and six introns. Sequence variation especially the polymorphic site changing the binding activity of certain transcription factor in promoter region hold great promise in altering the regulation of the gene's transcription and thereby modulating cancer risk. ${ }^{7}$ In recent years, an increasing number of studies investigated the association between polymorphisms of $O P N$ gene promoter region and risk of cancer. ${ }^{8-16}$ The most commonly studied $O P N$ promoter polymorphisms included rs28357094 (-66G/T), rs 17524488 (-156-/G), and rs11730582 (-443C/T). However, the results from individual studies were inconclusive.

Individual study possessed insufficient power to obtain a comprehensive and reliable conclusion due to limited sample size and ethnicities. Until now, no meta-analysis has been performed to explore the relation of $O P N$ gene promoter polymorphisms with risk of cancer. In order to provide insights into the role of promoter polymorphisms of $O P N$ gene in carcinogenesis, we perform a meta-analysis on the association between three most frequently studied $O P N$ promoter polymorphisms (rs28357094 G/T, rs 17524488 -/G, and rs11730582 C/T) and cancer risk.

\section{Materials and methods}

\section{Identification and eligibility of relevant studies}

Literatures of electronic databases including PubMed, Web of Science, and Chinese National Knowledge Infrastructure were systematically searched using different combinations of the search terms including "OPN/SPP1", "polymorphism/ mutation/variant", and "cancer/neoplasm/malignancy". References cited in each identified literatures were further searched manually for potential available studies. When overlapping data exists, only the largest and latest study was selected. We contacted the author for specific raw data if the data provided in the article were not sufficient. The last search date was October 5, 2014.

\section{Inclusion and exclusion criteria}

Studies included in this meta-analysis must meet the inclusion criteria as follows: case-control studies investigating the association between $O P N$ gene promoter polymorphisms (rs28357094, rs17524488, and rs11730582) and risk of cancer; studies with sufficient raw data for assessing odds ratios (ORs) and their 95\% confidence interval (CI); studies published in English or Chinese. Exclusion criteria were no relevance; reviews or letters; animal experiments for OPN; functional studies of OPN; duplicate publications; and not for rs17524488 or rs11730582 polymorphisms of OPN.

\section{Data extraction}

Two authors (Jingwei Liu and Caiyun He) independently extracted the data from the included studies. The following information was extracted from each study: name of first author, year of publication, ethnicity of the population, type of studied cancer, the source of the control group, numbers of cases and controls, and genotyping methods of $O P N$ polymorphism. The conflict was resolved after discussion, and consensus was finally reached on all of the extracted information.

\section{Statistical analysis}

The statistical analysis was performed by Stata software (Version 11.0; StataCorp, College Station, TX, USA). ORs and their 95\% CI were applied to assess the strength of association between $O P N$ gene polymorphisms and cancer risks. A $P$-value of $<0.05$ was considered as statistically significant. Heterogeneity was assessed by using Q statistic $(P<0.10$ indicates significant heterogeneity between studies) and I-squared $\left(I^{2}\right)$ value. ${ }^{17}$ A fixed-effects model using Mantel-Haenszel method ${ }^{18}$ was performed to calculate the pooled ORs when heterogeneity between studies was not significant. Otherwise, a random-effects model using DerSimonian and Laird method ${ }^{19}$ was used. Sensitivity analysis was carried out to explore heterogeneity when significant heterogeneity was indicated. Meta-regression was further conducted to investigate the source of heterogeneity. The between-studies variance $\left(\tau^{2}\right)$ was used to quantify the degree of heterogeneity between studies, and the percentage of $\tau^{2}$ was adopted to describe the extent of heterogeneity explained. ${ }^{20}$ Subgroup analyses were performed to explore the effects of genotyping methods and source of controls. In addition, publication bias was evaluated by Begg's test ${ }^{21}$ and Egger's test, ${ }^{22}$ respectively. $P$-value $<0.05$ for Begg's and Egger's tests suggests significant publication bias.

\section{Results}

\section{Characteristics of the included studies}

This meta-analysis was organized according to the PRISMA statement (Table $\mathrm{S} 1$ ). A total of 423 potentially relevant literatures were initially indentified through electronic databases 


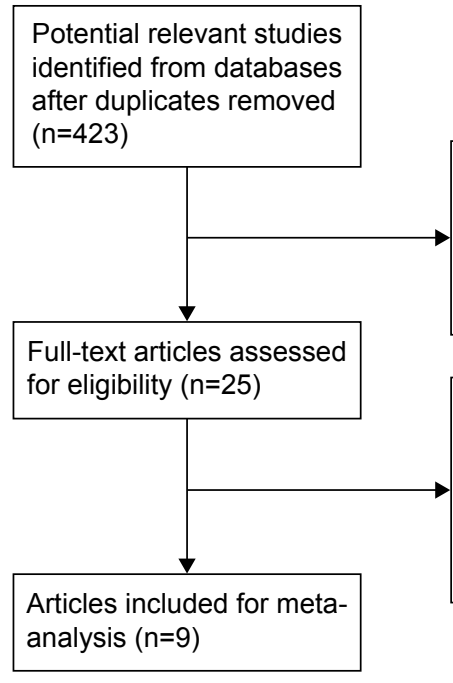

Figure I The flowchart of literature inclusion and exclusion. Abbreviation: OPN, osteopontin.

after duplicates removal. After carefully reviewing the titles and abstracts of these articles, 398 records were excluded due to no relevance, reviews or letters, and animal experiments. The remaining 25 full-text articles were further assessed for eligibility. Finally, nine articles were included in the present meta-analysis. ${ }^{8-16}$ The detailed flow chart of article selection was shown in Figure 1.

The main characteristics of the studies included in this meta-analysis were summarized in Table 1. No discrepancy was found between the two authors who performed the data extraction. All the included case-control studies were published in English or Chinese. The ethnicities of the studied populations were all Asians. Seven articles including 2,136 cases and 2,655 controls investigated the association between rs17524488 (-156-/G) polymorphism and risk of cancer; ${ }^{9,11-16}$ nine studies explored the relation of rs 11730582 $(-443 \mathrm{C} / \mathrm{T})$ polymorphism with risk of cancer. ${ }^{8-16}$ The types of cancers studied in relation to $O P N$ promoter polymorphisms included gastric cancer, thyroid cancer, lung cancer, cervical cancer, oral cancer, glioma, and liver cancer. The genotyping methods of $O P N$ promoter polymorphisms included sequencing, Taqman, and polymerase chain reaction/ligase detection reaction.

For $O P N$ promoter polymorphism rs $28357094(-66 \mathrm{G} / \mathrm{T})$, seven articles were included. It is worth noting that four of these studies ${ }^{9,11,12,14}$ did not find any individuals with GG or GT genotypes and all the cases and controls were TT genotype, which preclude us from further analyzing the data as the number of the study sample was very limited. Only two $\operatorname{articles}^{15,16}$ observed three different genotypes (GG, GT, and TT) and the genotyping method for them were both Taqman. Therefore, it still requires further research that whether the genotyping method had an impact on the results because sequencing and polymerase chain reaction/ligase detection reaction methods did not find any genetic variants of this polymorphism. The detailed information of the studies concerning the relation of $O P N$ promoter polymorphism

Table I Characteristics of the included studies in this meta-analysis

\begin{tabular}{|c|c|c|c|c|c|c|c|c|c|c|c|c|c|}
\hline \multirow[t]{2}{*}{ Author } & \multirow[t]{2}{*}{ Year } & \multirow[t]{2}{*}{ Ethnicity } & \multirow[t]{2}{*}{ Cancer type } & \multirow{2}{*}{$\begin{array}{l}\text { Controls } \\
\text { source }\end{array}$} & \multicolumn{4}{|l|}{ Case } & \multicolumn{4}{|c|}{ Control } & \multirow{2}{*}{$\begin{array}{l}\text { Genotyping } \\
\text { method }\end{array}$} \\
\hline & & & & & Total & MM & WM & WW & Total & MM & WM & WW & \\
\hline \multicolumn{14}{|c|}{ rs I 7524488/rs I | 439060 (- I 56-/G) } \\
\hline Mu et $\mathrm{al}^{15}$ & 2013 & Chinese & Thyroid cancer & $\mathrm{PB}$ & 363 & 72 & 187 & 104 & 413 & 94 & 219 & 100 & Taqman \\
\hline Lee et $\mathrm{al}^{14}$ & 2013 & Chinese & Gastric cancer & $\mathrm{HB}$ & 146 & 26 & 72 & 48 & 128 & 18 & 64 & 46 & Sequencing \\
\hline Chen et $\mathrm{al}^{13}$ & 2013 & Chinese & Lung cancer & PB & 360 & 73 & 150 & 137 & 360 & 69 & 136 & 155 & Sequencing \\
\hline Zhao et al $^{9}$ & 2012 & Chinese & Gastric cancer & PB & 200 & 41 & 92 & 67 & 200 & 36 & 78 & 86 & Sequencing \\
\hline Xu et al $^{16}$ & 2011 & Chinese & Cervical cancer & PB & 300 & 83 & 129 & 88 & 774 & 128 & 359 & 287 & Taqman \\
\hline Chiu et al" & 2010 & Chinese & Oral cancer & NA & 97 & 18 & 52 & 27 & 100 & 9 & 49 & 42 & Sequencing \\
\hline Chen et $\mathrm{al}^{12}$ & 2010 & Chinese & Glioma & $\mathrm{HB}$ & 664 & 99 & 345 & 220 & 669 & 90 & 306 & 273 & PCR-LDR \\
\hline \multicolumn{14}{|c|}{ rs I I $730582(-443 \mathrm{C} / \mathrm{T})$} \\
\hline Zhu $^{8}$ & 2013 & Chinese & Gastric cancer & $\mathrm{HB}$ & 106 & 16 & 46 & 44 & 106 & 12 & 41 & 53 & Sequencing \\
\hline Mu et $\mathrm{al}^{15}$ & 2013 & Chinese & Thyroid cancer & PB & 363 & 119 & $17 \mid$ & 73 & 413 & 62 & 187 & 164 & Taqman \\
\hline Lee et $\mathrm{al}^{14}$ & 2013 & Chinese & Gastric cancer & $\mathrm{HB}$ & 146 & 21 & 66 & 59 & 128 & 8 & 55 & 65 & Sequencing \\
\hline Chen et $\mathrm{al}^{13}$ & 2013 & Chinese & Lung cancer & PB & 360 & 31 & 165 & 164 & 360 & 44 & 163 & 153 & Sequencing \\
\hline Zhao et al $^{9}$ & 2012 & Chinese & Gastric cancer & PB & 200 & 15 & 94 & 91 & 200 & 22 & 93 & 85 & Sequencing \\
\hline $\mathrm{Xu}$ et $\mathrm{al}^{16}$ & 2011 & Chinese & Cervical cancer & PB & 300 & 24 & 49 & 227 & 774 & 106 & 334 & 334 & Taqman \\
\hline Chiu et al $^{\prime \prime}$ & 2010 & Chinese & Oral cancer & NA & 97 & 9 & 41 & 47 & 100 & 17 & 50 & 33 & Sequencing \\
\hline Chen et $\mathrm{al}^{12}$ & 2010 & Chinese & Glioma & $\mathrm{HB}$ & 667 & 69 & 299 & 299 & 672 & 77 & 311 & 284 & PCR-LDR \\
\hline Shin et $\mathrm{al}^{10, *}$ & 2007 & Korean & Liver cancer & $\mathrm{HB}$ & NA & NA & NA & NA & NA & NA & NA & NA & Taqman \\
\hline
\end{tabular}

Note: *Study with only allele information.

Abbreviations: PB, population-based; HB, hospital-based; W, wild-type allele; M, mutant-type allele; NA, not applicable; PCR-LDR, polymerase chain reaction/ligase detection reaction. 
rs28357094 (-66G/T), and the risk of cancer was summarized in Table $\mathrm{S} 1$.

\section{Association of OPN rs I 7524488 (-I56-/G) polymorphism with cancer risk}

Results of the association between $O P N$ rs 17524488 (-156-/G) polymorphism and cancer risk was summarized in Table 2. Carriers of GG genotype were observed to be significantly associated with increased risk of cancer compared with wildtype $-/$ - carriers $(\mathrm{OR}=1.40,95 \% \mathrm{CI}=1.03-1.91, P=0.033$, Figure 2). Individuals with -/G genotype were significantly associated with increased risk of cancer compared with wild-type -/- genotype $(\mathrm{OR}=1.22,95 \% \mathrm{CI}=1.07-1.40$, $P=0.002$, Figure 3 ). In addition, $\mathrm{G}$ allele was also significantly associated with increased risk of cancer compared with (-) allele $(\mathrm{OR}=1.21,95 \% \mathrm{CI}=1.04-1.40, P=0.016$, Figure $\mathrm{S} 1)$.

Subgroup analysis was performed to explore the effect of different genotyping methods and source of controls. For subgroup of sequencing method, OPN rs 17524488 (-156-/G) polymorphism was consistently associated with increased risk of cancer in all compared genetic models (GG vs -/-: OR $=1.41,95 \% \mathrm{CI}=1.07-1.87, P=0.016$; -/G vs GG: $\mathrm{OR}=1.32,95 \% \mathrm{CI}=1.06-1.65, P=0.012 ; \mathrm{G}$ allele vs $(-)$ allele: $\mathrm{OR}=1.23,95 \% \mathrm{CI}=1.07-1.42, P=0.004)$. For subgroup of Taqman method, however, no significant association was found in any of the compared genetic models. Besides, hospital-based subgroup demonstrated significant association of rs17524488 polymorphism with increased risk of cancer while no such association was observed in population-based subgroup.
Association of OPN rs I 730582 $(-443 \mathrm{C} / \mathrm{T})$ polymorphism with cancer risk Results of the association between OPN rs 11730582 $(-443 \mathrm{C} / \mathrm{T})$ polymorphism and cancer risk was summarized in Table 3. Carriers of CC or CT genotype were not significantly associated with altered risk of cancer compared with wild-type TT genotype (CC vs TT: OR $=0.98,95 \%$ $\mathrm{CI}=0.49-1.97, P=0.964$, Figure 3A; CT vs TT: $\mathrm{OR}=0.88$, $95 \% \mathrm{CI}=0.54-1.43, P=0.610$, Figure $3 \mathrm{~B}$ ). As for allele analysis, we did not observed any significant association of $O P N$ rs 11730582 (-443C/T) polymorphism and altered cancer risk $(\mathrm{C}$ allele vs $\mathrm{T}$ allele: $\mathrm{OR}=0.92,95 \% \mathrm{CI}=0.64-1.33$, $P=0.665$, Figure $\mathrm{S} 2$ ). Additionally, subgroup analyses based on genotyping method and source of controls also did not demonstrate any significant association between $O P N$ rs1 1730582 polymorphism and risk of cancer.

\section{Heterogeneity test, sensitivity analysis, and meta-regression}

In most comparisons of $O P N$ rs 11730582 (-443C/T) polymorphism and several comparisons of $O P N$ rs 17524488 (-156-/G) polymorphism, significant heterogeneity was observed. Subgroup analysis could not fully eliminate the heterogeneity. We subsequently performed sensitivity analysis to investigate the influence of individual study on the pooled estimate by omitting one study from the pooled analysis each time. The results indicated that no individual study significantly affected the pooled OR (figure not shown), suggesting that the outcomes of the meta-analysis were robust.

Table 2 Meta-analysis results of the association between OPN rs I7524488 (-I56-/G) polymorphism and cancer risk

\begin{tabular}{|c|c|c|c|c|c|c|c|}
\hline \multirow[t]{2}{*}{ Genetic model } & \multirow[t]{2}{*}{ Group/subgroup } & \multirow{2}{*}{$\begin{array}{l}\text { Studies } \\
\text { (n) }\end{array}$} & \multicolumn{2}{|c|}{ Heterogeneity test } & \multirow{2}{*}{$\begin{array}{l}\text { Statistical } \\
\text { model }\end{array}$} & \multicolumn{2}{|c|}{ Test for overall effect } \\
\hline & & & $I^{2}(\%)$ & $P_{\text {het }}$ & & OR (95\% CI) & $P$-value \\
\hline \multirow[t]{5}{*}{ GG vs $(-/-)$} & Overall & 7 & 65.90 & 0.007 & $\mathrm{R}$ & $1.40(1.03-1.91)$ & 0.033 \\
\hline & PB & 4 & 79.30 & 0.002 & $\mathrm{R}$ & $1.29(0.8 \mathrm{I}-2.05)$ & 0.290 \\
\hline & $\mathrm{HB}$ & 2 & 0.00 & 0.973 & $\mathrm{~F}$ & $1.37(1.01-1.86)$ & 0.044 \\
\hline & Sequencing & 4 & 12.10 & 0.332 & $\mathrm{~F}$ & 1.41 (1.07-1.87) & 0.016 \\
\hline & Taqman & 2 & 92.90 & $<0.001$ & $\mathrm{R}$ & $1.25(0.45-3.52)$ & 0.668 \\
\hline \multirow[t]{5}{*}{$(-/ G)$ vs $(-/-)$} & Overall & 7 & 31.40 & 0.188 & $\mathrm{~F}$ & $1.22(1.07-1.40)$ & 0.002 \\
\hline & PB & 4 & 46.10 & 0.135 & $\mathrm{~F}$ & $1.13(0.95-1.34)$ & 0.163 \\
\hline & $\mathrm{HB}$ & 2 & 0.00 & 0.376 & $\mathrm{~F}$ & $1.34(1.08-1.66)$ & 0.008 \\
\hline & Sequencing & 4 & 0.00 & 0.670 & $\mathrm{~F}$ & $1.32(1.06-1.65)$ & 0.012 \\
\hline & Taqman & 2 & 56.60 & 0.129 & $\mathrm{~F}$ & $0.99(0.79-1.25)$ & 0.964 \\
\hline \multirow[t]{5}{*}{ G allele vs (-) allele } & Overall & 7 & 66.00 & 0.007 & $\mathrm{R}$ & $1.21(1.04-1.40)$ & 0.016 \\
\hline & PB & 4 & 79.80 & 0.002 & $\mathrm{R}$ & $1.16(0.91-1.48)$ & 0.222 \\
\hline & $\mathrm{HB}$ & 2 & 0.00 & 0.787 & $\mathrm{~F}$ & $1.20(1.04-1.39)$ & 0.011 \\
\hline & Sequencing & 4 & 0.00 & 0.432 & $\mathrm{~F}$ & $1.23(1.07-1.42)$ & 0.004 \\
\hline & Taqman & 2 & 93.00 & $<0.001$ & $\mathrm{R}$ & $1.13(0.67-1.90)$ & 0.655 \\
\hline
\end{tabular}

Note: Significant results are marked in bold.

Abbreviations: OPN, osteopontin; R, random-effect model; F, fixed-effect model; PB, population-based; HB, hospital-based; OR, odds ratio; Cl, confidence interval; $P_{\text {het' }}$ $P$-value for heterogeneity test. 


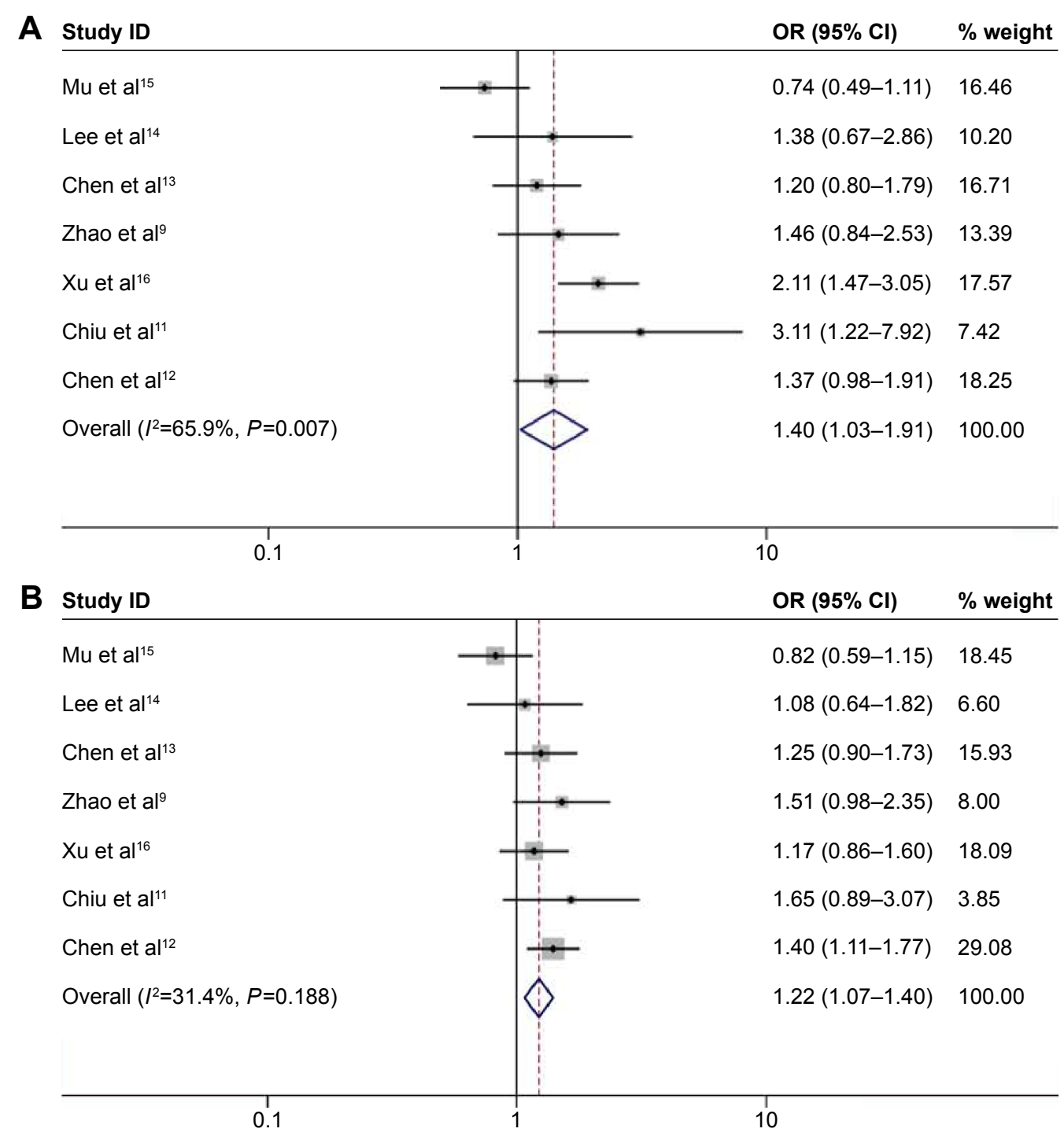

Figure 2 Forest plots for the association between OPN rs I7524488 (-I56-/G) polymorphism and cancer risk.

Notes: (A) Forest plot for the association between OPN rsI7524488 (-I56-/G) polymorphism and cancer risk (GG vs -/-); (B) Forest plot for the association between OPN rs I7524488 (-I56-/G) polymorphism and cancer risk (-G vs -/-). Weights are from random-effects analysis.

Abbreviations: OPN, osteopontin; OR, odds ratio; $\mathrm{Cl}$, confidence interval.

Meta-regression was therefore conducted to explore the source of the heterogeneity in the association between $O P N$ rs11730582 (-443C/T) polymorphism and risk of cancer. The results of meta-regression suggested that none of the factors including cancer type $(P=0.168)$, control source $(P=0.800)$, and genotyping method $(P=0.350)$ significantly contributed to the source of heterogeneity for CC vs TT comparison. For CT vs TT comparison, none of cancer type $(P=0.429)$, control source $(P=0.756)$, and genotyping method $(P=0.792)$ significantly contributed to the source of heterogeneity.

\section{Publication bias}

The Begg's test and Egger's test were performed to quantitatively assess the publication bias of the included studies.
The detailed information for publication bias test was shown in Table 4. For both the associations of $O P N$ rs 17524488 $(-156-/ \mathrm{G})$ polymorphism and $O P N$ rs $11730582(-443 \mathrm{C} / \mathrm{T})$ polymorphism with cancer risk, no significant publication bias was observed in the present meta-analysis.

\section{Discussion}

Previous individual studies concerning the associations between $O P N$ promoter polymorphisms and cancer risk came up with inconsistent results. This meta-analysis investigated the role of $O P N$ promoter polymorphisms (rs28357094 G/T, rs17524488 -/G, and rs11730582 C/T) in carcinogenesis. Through analyzing the data extracted from previous full-text publications, we revealed that $O P N$ rs17524488 (-156-/G) 


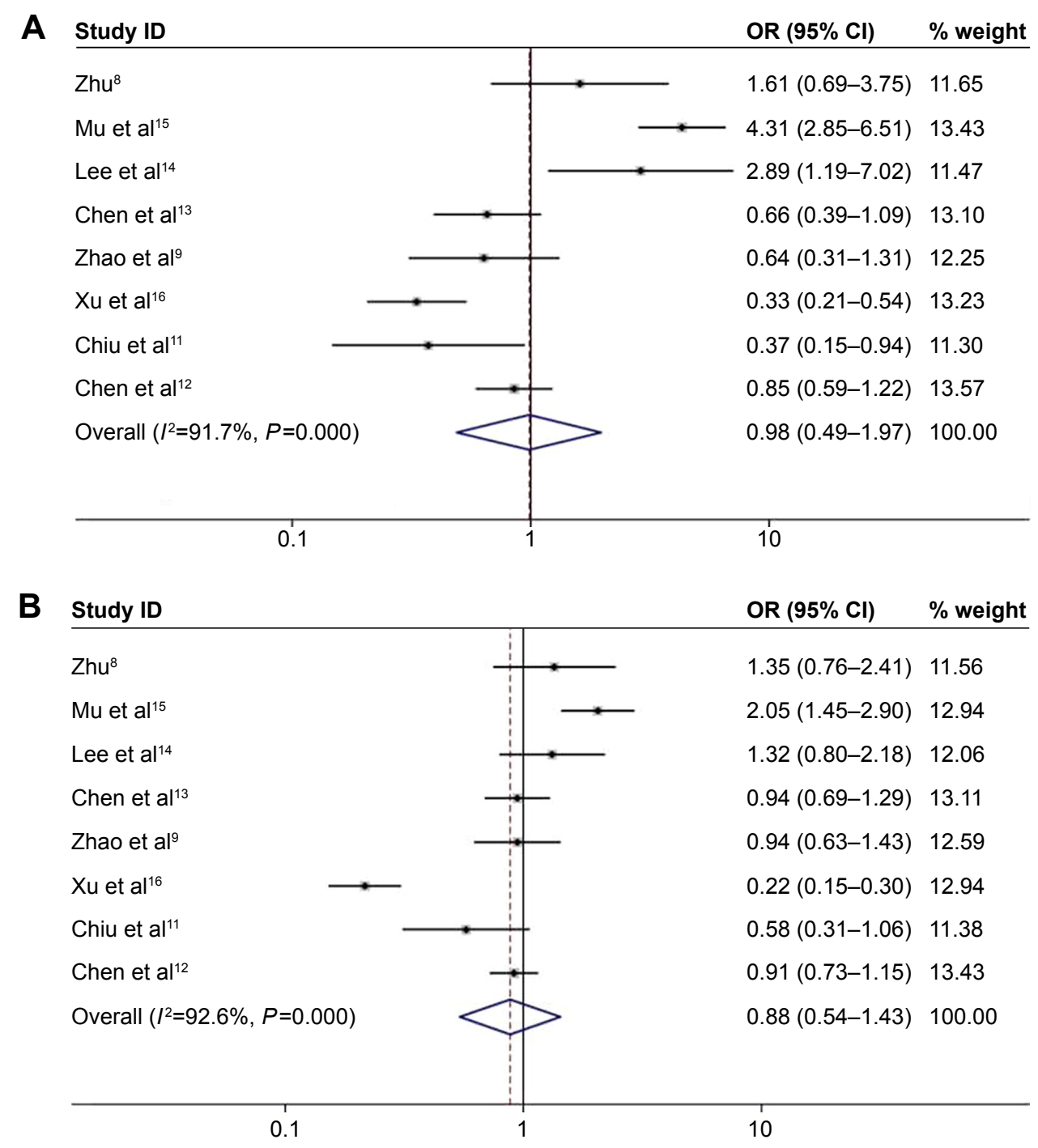

Figure 3 Forest plots for the association between OPN rs I I $730582(-443 \mathrm{C} / \mathrm{T})$ polymorphism and cancer risk.

Notes: (A) Forest plot for the association between OPN rs I I 730582 (-443C/T) polymorphism and cancer risk (CC vs TT); (B) Forest plot for the association between OPN rs I I730582 (-443C/T) polymorphism and cancer risk (CT vs TT). Weights are from random-effects analysis.

Abbreviations: OPN, osteopontin; OR, odds ratio; $\mathrm{Cl}$, confidence interval.

Table 3 Meta-analysis results of the association between OPN rs I I 730582 (-443C/T) polymorphism and cancer risk

\begin{tabular}{|c|c|c|c|c|c|c|c|}
\hline \multirow[t]{2}{*}{ Genetic model } & \multirow[t]{2}{*}{ Group/subgroup } & \multirow[t]{2}{*}{$\mathbf{N}$} & \multicolumn{2}{|c|}{ Heterogeneity test } & \multirow{2}{*}{$\begin{array}{l}\text { Statistical } \\
\text { model }\end{array}$} & \multicolumn{2}{|c|}{ Test for overall effect } \\
\hline & & & $I^{2}(\%)$ & $\boldsymbol{P}_{\text {het }}$ & & OR $(95 \% \mathrm{CI})$ & $P$-value \\
\hline \multirow[t]{5}{*}{ CC vs TT } & Overall & 8 & 91.70 & $<0.001$ & $\mathrm{R}$ & $0.98(0.49-1.97)$ & 0.964 \\
\hline & PB & 4 & 95.90 & $<0.001$ & $\mathrm{R}$ & $0.89(0.25-3.11)$ & 0.852 \\
\hline & $\mathrm{HB}$ & 3 & 72.30 & 0.027 & $\mathrm{R}$ & $1.45(0.68-3.09)$ & 0.333 \\
\hline & Sequencing & 5 & 71.70 & 0.007 & $\mathrm{R}$ & $0.92(0.49-1.73)$ & 0.787 \\
\hline & Taqman & 2 & 98.40 & $<0.001$ & $\mathrm{R}$ & $1.20(0.10-14.78)$ & 0.886 \\
\hline \multirow[t]{5}{*}{ CT vs TT } & Overall & 8 & 92.60 & $<0.001$ & $\mathrm{R}$ & $0.88(0.54-1.43)$ & 0.610 \\
\hline & PB & 4 & 96.50 & $<0.001$ & $\mathrm{R}$ & $0.79(0.3 \mathrm{I}-2.02)$ & 0.627 \\
\hline & $\mathrm{HB}$ & 3 & 29.20 & 0.243 & $\mathrm{~F}$ & $1.01(0.83-1.23)$ & 0.925 \\
\hline & Sequencing & 5 & 28.30 & 0.233 & $\mathrm{~F}$ & $0.98(0.8 \mathrm{I}-\mathrm{I} .20)$ & 0.863 \\
\hline & Taqman & 2 & 98.80 & $<0.001$ & $\mathrm{R}$ & $0.67(0.07-6.06)$ & 0.718 \\
\hline \multirow[t]{5}{*}{$\mathrm{C}$ allele vs $\mathrm{T}$ allele } & Overall & 9 & 94.40 & $<0.001$ & $\mathrm{R}$ & $0.92(0.64-1.33)$ & 0.665 \\
\hline & PB & 4 & 96.70 & $<0.001$ & $\mathrm{R}$ & $0.87(0.40-1.87)$ & 0.715 \\
\hline & $\mathrm{HB}$ & 4 & 72.80 & 0.012 & $\mathrm{R}$ & $1.06(0.80-1.39)$ & 0.683 \\
\hline & Sequencing & 5 & 73.20 & 0.005 & $\mathrm{R}$ & $0.97(0.73-1.29)$ & 0.860 \\
\hline & Taqman & 3 & 98.40 & $<0.001$ & $\mathrm{R}$ & $0.84(0.28-2.54)$ & 0.756 \\
\hline
\end{tabular}

Abbreviations: OPN, osteopontin; R, random-effect model; $\mathrm{F}$, fixed-effect model; $\mathrm{PB}$, population-based; HB, hospital-based; OR, odds ratio; $\mathrm{Cl}$, confidence interval; $P_{\text {het' }}$ $P$-value for heterogeneity test. 
polymorphism was significantly associated with increased cancer risk, but no significant association was observed of OPN rs11730582 (-443C/T) polymorphism with altered risk of cancer. Additionally, the frequency of $\mathrm{G}$ allele of rs28357094 (-66G/T) polymorphism was very low that no further analysis was performed.

Osteopontin, first detected in 1979, is a secreted phosphorylated protein expressed in a variety of tissues as well as bodily fluids with cell-adhesive and chemotactic properties. ${ }^{23}$ Osteopontin contains several functional domains such as calcium-binding domain, RGD (arginine-glycine-aspartic acid) sequence and thrombin cleavage site, which is important for binding to integrins and CD44. ${ }^{24} \mathrm{OPN}$ is initially known to display several functions in different physiological and pathological processes, including cell-mediated immunity, bone remodeling, maintenance or reconfiguration of tissue integrity during inflammatory processes. ${ }^{25}$ Subsequently, it has been reported that OPN was overexpressed in various kinds of cancers including gastric, colon, renal, pancreatic, lung, and prostate cancers. ${ }^{26}$ The expression of OPN in different cell types was significantly influenced by its genetic polymorphisms of the promoter. ${ }^{27}$ Considering the potential role of OPN in carcinogenesis, much attention has recently been paid to the relation of $O P N$ promoter polymorphism (rs28357094 G/T, rs17524488 -/G, and rs11730582 C/T) and risk of cancer, but the results were inconclusive.

In this meta-analysis, we revealed that carriers of GG or -/G genotype of $O P N$ promoter rs 17524488 (-156-/G) polymorphism were significantly associated with increased risk of cancer compared with wild-type -/- carriers, respectively (GG vs -/-: OR =1.40, $P=0.033$; -/G vs GG: $\mathrm{OR}=1.22$, $P=0.002)$. As for allele analysis, $\mathrm{G}$ allele was significantly associated with increased risk of cancer compared with (-) allele $(\mathrm{OR}=1.21, P=0.016)$. Subgroup of sequencing demonstrated that $O P N$ rs $17524488(-156-/ \mathrm{G})$ polymorphism was consistently associated with increased risk of cancer in all compared genetic models (GG vs -/-: OR =1.41; -/G vs $\mathrm{GG}$ : $\mathrm{OR}=1.32$; $\mathrm{G}$ allele vs $(-)$ allele: $\mathrm{OR}=1.23)$. However, no such significant association was observed in any compared genetic models for subgroup of Taqman method, which indicated that the genotyping method may have an impact on the relation of this polymorphism and cancer risk. Additionally, hospital-based subgroup demonstrated significant association of rs 17524488 polymorphism with increased risk of cancer while no significant association was found in population-based subgroup, suggesting that the source of controls adopted might influence the association of this polymorphism with cancer risk. For OPN rs11730582 (-443C/T) polymorphism, no significant association was observed with risk of cancer in any of the genetic models (CC vs TT: $\mathrm{OR}=0.98, P=0.964 ; \mathrm{CT}$ vs TT: $\mathrm{OR}=0.88, P=0.610 ; \mathrm{C}$ allele vs T allele: $\mathrm{OR}=0.92, P=0.665)$. Besides, subgroup analysis also did not reveal any significant association.

Emerging evidence has suggested that OPN has an important role in tumorigenesis. ${ }^{28,29}$ It has been reported that polymorphisms in the $O P N$ gene promoter can affect its transcriptional activity and rs17524488 (-156-/G) polymorphism is located at the binding site of transcriptional factor RUNX2 ${ }^{30,31}$ Reporter gene expression experiments with the $O P N$ promoter polymorphisms revealed that the sequence variants $\mathrm{G}$-insertion at position 155 in combination with the $66 \mathrm{~T}$ allele resulted in a significantly increased reporter gene expression. ${ }^{30}$ Additionally, RUNX2 factor was shown to bind better to the $\mathrm{G}$ allele than to the (-) allele of rs 17524488 (-156-/G) polymorphism. ${ }^{30}$ As a result, the rs $17524488(-/ \mathrm{G})$ polymorphism located at promoter region (-156) of $O P N$ gene might influence the binding affinity of transcriptional factors and promoter activity, thereby altering OPN expression. Individual genotypes of the $O P N$ promoter rs 17524488 (-/G) polymorphism might display different regulatory efficiencies by transcription factors including RUNX2, resulting in diverse susceptibilities for cancer. Although the abovementioned studies might partly account for the observed significant association between $O P N$ promoter rs 17524488 $(-156-/ G)$ polymorphism and increased risk of cancer, future functional and mechanism investigations are still warranted. In addition, we were aware that a meta-analysis by Liu et $\mathrm{al}^{32}$ also investigated the association of OPN polymorphism and risk of cancer. But the present study had certain differences: First, the previous meta-analysis only focused on Chinese population while our meta-analysis included all available ethnicities, which could increase the applicability of the results. Second, we also search database of Chinese National Knowledge Infrastructure for literatures published in Chinese and further unpublished data. Furthermore, we performed allele analysis of OPN promoter polymorphisms and subgroup analysis based on different genotyping methods to explore more available results. Further large-scale and well-designed investigations are still required to confirm the results of our meta-analysis.

Several limitations should be acknowledged in the present meta-analysis. First, the studied sample was relatively not large enough especially for certain subgroup analysis. Second, obvious heterogeneity was observed in the comparisons of $O P N$ promoter rs $11730582(-443 \mathrm{C} / \mathrm{T})$ polymorphism and risk of cancer, which could not be fully explained by 
Table 4 Results of publication bias test

\begin{tabular}{|c|c|c|c|c|c|}
\hline \multirow[t]{2}{*}{ Polymorphism } & \multirow[t]{2}{*}{ Compared genotype } & \multicolumn{2}{|c|}{ Begg's test } & \multicolumn{2}{|c|}{ Egger's test } \\
\hline & & z-value & $P$-value & $t$-value & $P$-value \\
\hline \multirow[t]{3}{*}{ OPN rsI7524488 (-I56-/G) } & GG vs (-/-) & 0.45 & 0.652 & 0.53 & 0.620 \\
\hline & $(-/ G)$ vs $(-/-)$ & -0.45 & 0.652 & 0.02 & 0.986 \\
\hline & G allele vs (-) allele & 0.45 & 0.652 & 0.47 & 0.656 \\
\hline \multirow[t]{3}{*}{ OPN rsI I $730582(-443 \mathrm{C} / \mathrm{T})$} & CC vs TT & 0.00 & 1.000 & -0.23 & 0.823 \\
\hline & CT vs TT & 0.00 & 1.000 & 0.10 & 0.924 \\
\hline & $\mathrm{C}$ allele vs $\mathrm{T}$ allele & -0.42 & 0.677 & -0.22 & 0.829 \\
\hline
\end{tabular}

Abbreviation: OPN, osteopontin.

subgroup analysis and meta-regression. Third, the ethnicities of all the included studies were Asians, which inevitably limited the generalizability of our conclusion. Fourth, other important raw data such as age, sex, and family history were not available for each individual study so that we could not obtain results with adjustments by other co-variables. Fifth, the combination of the data from different types of cancers and different sequencing methods may lead to the population heterogeneous and decreased the power of the study.

\section{Conclusion}

In summary, this meta-analysis indicated that carriers of GG or -/G genotype of $O P N$ promoter rs17524488 (-156-/G) polymorphism might be associated with increased risk of cancer compared with wild-type -/- carriers, respectively. However, no significant association was observed between $O P N$ promoter rs11730582 (-443C/T) polymorphism and risk of cancer. Further large-scale and well-designed investigations concerning different ethnicities are still required to confirm the results of our meta-analysis.

\section{Acknowledgments}

This study was supported by grants from National Basic Research Program of China (973 program reference number 2010CB529304) and the grants of the Science and Technology Project of Liaoning Province (reference numbers 2011225002 and 2012225016).

\section{Author contributions}

Jingwei Liu and Caiyun He performed statistical analysis, data interpretation, and wrote the paper. Quan Yuan and Zhenning Wang analyzed the data and revised the manuscript. Chengzhong Xing and Yuan Yuan conceived this study and revised the manuscript. All authors contributed toward data analysis, drafting and critically revising the paper, read and approved the final manuscript version to be published, and agree to be accountable for all aspects of the work.

\section{Disclosure}

The authors report no conflicts of interest in this work.

\section{References}

1. Jemal A, Bray F, Center MM, Ferlay J, Ward E, Forman D. Global cancer statistics. CA Cancer J Clin. 2011;61(2):69-90.

2. Zaridze DG. Molecular epidemiology of cancer. Biochemistry (Mosc). 2008;73(5):532-542.

3. Cao DX, Li ZJ, Jiang XO, et al. Osteopontin as potential biomarker and therapeutic target in gastric and liver cancers. World J Gastroenterol. 2012; 18(30):3923-3930.

4. Shevde LA, Das S, Clark DW, Samant RS. Osteopontin: an effector and an effect of tumor metastasis. Curr Mol Med. 2010;10(1):71-81.

5. Denhardt DT, Lopez CA, Rollo EE, Hwang SM, An XR, Walther SE. Osteopontin-induced modifications of cellular functions. Ann NY Acad Sci. 1995;760:127-142.

6. McAllister SS, Gifford AM, Greiner AL, et al. Systemic endocrine instigation of indolent tumor growth requires osteopontin. Cell. 2008; 133(6):994-1005.

7. Trzyna E, Duleba M, Faryna M, Majka M. Regulation of transcription in cancer. Front Biosci (Landmark Ed). 2012;17:316-330.

8. Zhu H. Relationship between the variations of OPN $-443 T / C$ site and different gastric diseases [dissertation]. Changchun, People's Republic of China: Jilin University; 2013.

9. Zhao F, Chen X, Meng T, Hao B, Zhang Z, Zhang G. Genetic polymorphisms in the osteopontin promoter increases the risk of distance metastasis and death in Chinese patients with gastric cancer. $B M C$ Cancer. 2012;12:477.

10. Shin HD, Park BL, Cheong HS, Yoon JH, Kim YJ, Lee HS. SPP1 polymorphisms associated with $\mathrm{HBV}$ clearance and HCC occurrence. Int J Epidemiol. 2007;36(5):1001-1008.

11. Chiu YW, Tu HF, Wang IK, et al. The implication of osteopontin (OPN) expression and genetic polymorphisms of OPN promoter in oral carcinogenesis. Oral Oncol. 2010;46(4):302-306.

12. Chen J, Wu Q, Lu Y, et al. SPP1 promoter polymorphisms and glioma risk in a Chinese Han population. J Hum Genet. 2010;55(7):456-461.

13. Chen Y, Liu H, Wu W, Li Y, Li J. Osteopontin genetic variants are associated with overall survival in advanced non-small-cell lung cancer patients and bone metastasis. J Exp Clin Cancer Res. 2013;32:45.

14. Lee TY, Lin JT, Wu CC, et al. Osteopontin promoter polymorphisms are associated with susceptibility to gastric cancer. J Clin Gastroenterol. 2013;47(6):E55-E59.

15. Mu G, Wang H, Cai Z, Ji H. OPN $-443 \mathrm{C}>$ T genetic polymorphism and tumor OPN expression are associated with the risk and clinical features of papillary thyroid cancer in a Chinese cohort. Cell Physiol Biochem. 2013;32(1):171-179.

16. Xu Q, Yuan B, Xue F, et al. OPN gene polymorphisms are associated with susceptibility and clinicopathological characteristics of cervical cancer in a Chinese cohort. Cancer Biomark. 2011;10(5):233-239.

17. Higgins JP, Thompson SG. Quantifying heterogeneity in a metaanalysis. Stat Med. 2002;21(11):1539-1558. 
18. Mantel N, Haenszel W. Statistical aspects of the analysis of data from retrospective studies of disease. J Natl Cancer Inst. 1959;22(4): 719-748.

19. DerSimonian R, Laird N. Meta-analysis in clinical trials. Control Clin Trials. 1986;7(3):177-188.

20. Whitehead A, Whitehead J. A general parametric approach to the meta-analysis of randomized clinical trials. Stat Med. 1991;10(11): 1665-1677.

21. Begg CB, Mazumdar M. Operating characteristics of a rank correlation test for publication bias. Biometrics. 1994;50(4):1088-1101.

22. Egger M, Davey Smith G, Schneider M, Minder C. Bias in meta-analysis detected by a simple, graphical test. BMJ. 1997;315(7109):629-634.

23. Sodek J, Ganss B, McKee MD. Osteopontin. Crit Rev Oral Biol Med. 2000;11(3):279-303.

24. Bellahcene A, Castronovo V, Ogbureke KU, Fisher LW, Fedarko NS. Small integrin-binding ligand N-linked glycoproteins (SIBLINGs): multifunctional proteins in cancer. Nat Rev Cancer. 2008;8(3): 212-226

25. Wang KX, Denhardt DT. Osteopontin: role in immune regulation and stress responses. Cytokine Growth Factor Rev. 2008;19(5-6): 333-345.

26. Coppola D, Szabo M, Boulware D, et al. Correlation of osteopontin protein expression and pathological stage across a wide variety of tumor histologies. Clin Cancer Res. 2004;10(1 Pt 1):184-190.
27. El-Tanani MK, Campbell FC, Kurisetty V, Jin D, McCann M, Rudland PS. The regulation and role of osteopontin in malignant transformation and cancer. Cytokine Growth Factor Rev. 2006;17(6):463-474.

28. Hsieh YH, Juliana MM, Hicks PH, et al. Papilloma development is delayed in osteopontin-null mice: implicating an antiapoptosis role for osteopontin. Cancer Res. 2006;66(14):7119-7127.

29. Chang PL, Hsieh YH, Wang CC, et al. Osteopontin facilitates ultraviolet B-induced squamous cell carcinoma development. J Dermatol Sci. 2014;75(2):121-132.

30. Giacopelli F, Marciano R, Pistorio A, et al. Polymorphisms in the osteopontin promoter affect its transcriptional activity. Physiol Genomics. 2004;20(1):87-96.

31. Hummelshoj T, Ryder LP, Madsen HO, Odum N, Svejgaard A. A functional polymorphism in the Eta-1 promoter is associated with allele specific binding to the transcription factor $\mathrm{Sp} 1$ and elevated gene expression. Mol Immunol. 2006;43(7):980-986.

32. Liu Y, Lei H, Zhang J, Wang J, Li K, Dong W. Associations between the genetic polymorphisms of osteopontin promoter and susceptibility to cancer in Chinese population: a meta-analysis. PLoS One. 2015;10(8): e0135318. 


\section{Supplementary materials}

PRISMA checklist

Table SI Information of studies concerning the relation of OPN promoter polymorphism rs28357094 (-66G/T) and risk of cancer

\begin{tabular}{|c|c|c|c|c|c|c|c|c|c|c|c|}
\hline \multirow[t]{2}{*}{ Author } & \multirow[t]{2}{*}{ Year } & \multirow[t]{2}{*}{ Ethnicity } & \multirow[t]{2}{*}{ Cancer type } & \multirow{2}{*}{$\begin{array}{l}\text { Controls } \\
\text { source }\end{array}$} & \multicolumn{3}{|c|}{ Case } & \multicolumn{3}{|c|}{ Control } & \multirow{2}{*}{$\begin{array}{l}\text { Genotyping } \\
\text { method }\end{array}$} \\
\hline & & & & & GG & GT & TT & GG & GT & TT & \\
\hline Mu et al ${ }^{\prime}$ & 2013 & Chinese & Thyroid cancer & PB & 97 & 167 & 99 & 108 & 191 & 114 & Taqman \\
\hline Lee et $\mathrm{al}^{2}$ & 2013 & Chinese & Gastric cancer & $\mathrm{HB}$ & 0 & 0 & 146 & 0 & 0 & 128 & Sequencing \\
\hline Chen et $\mathrm{al}^{3}$ & 2013 & Chinese & Lung cancer & PB & 0 & 4 & 356 & 0 & 9 & 351 & Sequencing \\
\hline Zhao et $\mathrm{al}^{4}$ & 2012 & Chinese & Gastric cancer & PB & 0 & 0 & 200 & 0 & 0 & 200 & Sequencing \\
\hline Xu et $\mathrm{al}^{5}$ & 2011 & Chinese & Cervical cancer & PB & 113 & 90 & 97 & 235 & 358 & 181 & Taqman \\
\hline Chiu et $\mathrm{al}^{6}$ & 2010 & Chinese & Oral cancer & NA & 0 & 0 & 97 & 0 & 0 & 100 & Sequencing \\
\hline Chen et $\mathrm{al}^{7}$ & 2010 & Chinese & Glioma & $\mathrm{HB}$ & 0 & 0 & 670 & 0 & 0 & 680 & PCR-LDR \\
\hline
\end{tabular}

Abbreviations: OPN, osteopontin; PB, population-based; HB, hospital-based; NA, not applicable; PCR-LDR, polymerase chain reaction/ligase detection reaction.

\begin{tabular}{|c|c|c|}
\hline Study ID & OR $(95 \% \mathrm{Cl})$ & $\%$ weight \\
\hline Mu et $\mathrm{al}^{1}$ & $0.86(0.71-1.05)$ & 16.48 \\
\hline Lee et $\mathrm{al}^{2}$ & $1.15(0.82-1.62)$ & 10.63 \\
\hline Chen et $\mathrm{al}^{3}$ & $1.14(0.92-1.40)$ & 15.94 \\
\hline Zhao et $\mathrm{al}^{4}$ & $1.28(0.97-1.70)$ & 12.80 \\
\hline Xu et $\mathrm{al}^{5}$ & $1.47(1.21-1.77)$ & 16.96 \\
\hline Chiu et $\mathrm{al}^{6}$ & $1.65(1.10-2.48)$ & 8.66 \\
\hline Chen et $\mathrm{al}^{7}$ & $1.21(1.04-1.42)$ & 18.54 \\
\hline Overall $\left(I^{2}=66.0 \%, P=0.007\right)$ & $1.21(1.04-1.40)$ & 100.00 \\
\hline
\end{tabular}

Figure SI Forest plot for the association between OPN rs I7524488 (-I56-/G) polymorphism and cancer risk (G allele vs - allele).

Note: Weights are from random-effects analysis.

Abbreviations: OPN, osteopontin; OR, odds ratio; $\mathrm{Cl}$, confidence interval.

\begin{tabular}{|c|c|c|}
\hline Study ID & OR $(95 \% \mathrm{Cl})$ & $\%$ weight \\
\hline Zhu ${ }^{8}$ & $1.32(0.88-1.97)$ & 10.45 \\
\hline Mu et $\mathrm{al}^{1}$ & $2.14(1.74-2.62)$ & 11.56 \\
\hline Lee et $\mathrm{al}^{2}$ & $1.53(1.06-2.20)$ & 10.72 \\
\hline Chen et $\mathrm{al}^{3}$ & $0.86(0.69-1.07)$ & 11.49 \\
\hline Zhao et $\mathrm{al}^{4}$ & $0.86(0.64-1.16)$ & 11.11 \\
\hline Xu et $\mathrm{al}^{5}$ & $0.35(0.28-0.45)$ & 11.39 \\
\hline Chiu et $a^{6}$ & $0.60(0.40-0.91)$ & 10.37 \\
\hline Chen et $\mathrm{al}^{7}$ & $0.92(0.78-1.08)$ & 11.72 \\
\hline Shin et $\mathrm{al}^{9}$ & $0.78(0.59-1.03)$ & 11.19 \\
\hline Overall $\left(I^{2}=94.4 \%, P=0.000\right)$ & $0.92(0.64-1.33)$ & 100.00 \\
\hline
\end{tabular}

Figure S2 Forest plot for the association between OPN rs I I 730582 (-443C/T) polymorphism and cancer risk (C allele vs T allele).

Note: Weights are from random-effects analysis.

Abbreviations: OPN, osteopontin; OR, odds ratio; $\mathrm{Cl}$, confidence interval. 


\section{References}

1. Mu G, Wang H, Cai Z, Ji H. OPN $-443 \mathrm{C}>\mathrm{T}$ genetic polymorphism and tumor OPN expression are associated with the risk and clinical features of papillary thyroid cancer in a Chinese cohort. Cell Physiol Biochem. 2013;32(1):171-179.

2. Lee TY, Lin JT, Wu CC, et al. Osteopontin promoter polymorphisms are associated with susceptibility to gastric cancer. J Clin Gastroenterol. 2013;47(6):E55-E59.

3. Chen Y, Liu H, Wu W, Li Y, Li J. Osteopontin genetic variants are associated with overall survival in advanced non-small-cell lung cancer patients and bone metastasis. J Exp Clin Cancer Res. 2013;32:45.

4. Zhao F, Chen X, Meng T, Hao B, Zhang Z, Zhang G. Genetic polymorphisms in the osteopontin promoter increases the risk of distance metastasis and death in Chinese patients with gastric cancer. $B M C$ Cancer. 2012;12:477.
5. Xu Q, Yuan B, Xue F, et al. OPN gene polymorphisms are associated with susceptibility and clinicopathological characteristics of cervical cancer in a Chinese cohort. Cancer Biomark. 2011;10(5):233-239.

6. Chiu YW, Tu HF, Wang IK, et al. The implication of osteopontin (OPN) expression and genetic polymorphisms of OPN promoter in oral carcinogenesis. Oral Oncol. 2010;46(4):302-306.

7. Chen J, Wu Q, Lu Y, et al. SPP1 promoter polymorphisms and glioma risk in a Chinese Han population. J Hum Genet. 2010;55(7):456-461.

8. Zhu H. Relationship between the variations of OPN-443T/C site and different gastric diseases. 2013.

9. Shin HD, Park BL, Cheong HS, Yoon JH, Kim YJ, Lee HS. SPP1 polymorphisms associated with HBV clearance and HCC occurrence. Int J Epidemiol. 2007;36(5):1001-1008.

\section{Publish your work in this journal}

OncoTargets and Therapy is an international, peer-reviewed, open access journal focusing on the pathological basis of all cancers, potential targets for therapy and treatment protocols employed to improve the management of cancer patients. The journal also focuses on the impact of management programs and new therapeutic agents and protocols on

\section{Dovepress}

patient perspectives such as quality of life, adherence and satisfaction. The manuscript management system is completely online and includes a very quick and fair peer-review system, which is all easy to use. Visit http://www.dovepress.com/testimonials.php to read real quotes from published authors.

Submit your manuscript here: http://www.dovepress.com/oncotargets-and-therapy-journal 